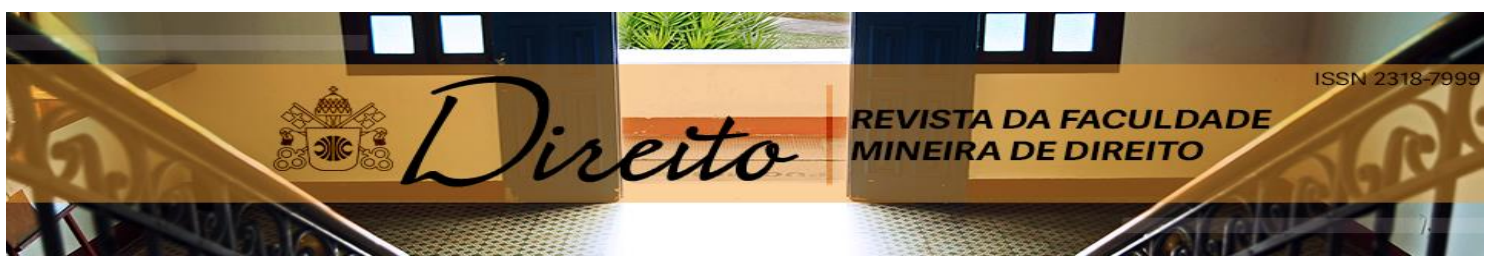

\title{
SINDICATOS, DIÁLOGO SOCIAL Y EMPLEO EN EUROPA OCCIDENTAL. UNA APROXIMACIÓN AL CASO DE ESPAÑA EN PERSPECTIVA COMPARADA
}

\author{
TRADE UNIONS, SOCIAL DIALOGUE AND EMPLOYMENT IN WESTERN EUROPE. \\ AN APPROACH TO THE CASE OF SPAIN IN A COMPARATIVE PERSPECTIVE
}

Marcial Sánchez Mosquera

\begin{abstract}
Resumen
Este artículo presenta un estudio preliminar de los sindicatos españoles más representativos como agentes de cambio y regulación de los mercados de trabajo a través del diálogo social entre 1996 y 2013 en perspectiva comparada con el área de Europa Occidental. Para conseguir este propósito, se plantea un estudio la evolución del diálogo social en España desde 1996 a 2013, con especial atención a los cambios operados sobre el mercado de trabajo y su impacto sobre la evolución de las tasas de desempleo. Siguiendo la metodología propuesta, se ha concluido los escasos resultados logrados por las reformas pactadas para mejorar la eficacia y calidad del mercado de trabajo español. Tal insuficiencia, que no mejoró sustancialmente la posición de partida de los indicadores españoles frente a la media de los países de su entorno, ha permanecido invariable. Últimamente, la ruptura del diálogo social y las dos últimas reformas, por iniciativa unilateral del Gobierno, han hecho que empore la situación.
\end{abstract}

Palabras-Clave: sindicatos, diálogo social, empleo, reforma del mercado de trabajo.

\begin{abstract}
This paper presents a preliminary version of the case study of most representative trade unions in Spain, as agents of change and regulation of labour markets through social dialogue between 1996 and 2013 within the context of Western Europe. In order to achieve the purposes outlined in the first heading, it is examined the developments of social dialogue in Spain from 1996 to 2013, with particular emphasis on changes in the labour market and its impact on the evolution of unemployment rates. The following heading focuses on the methodology adopted and the implementation to the Spanish case, with an explanation of the adopted approach, indicators analysed and key questions that have guided the present research. From there on, a new paragraph is opened in which the stages of social dialogue and registered conflicts in Spain are defined, the result of social pacts reforms are analysed, the impact on labour market in comparative perspective is evaluated and, finally, the effects on trade unions. Ultimately, the breakdown of social dialogue and the last two labour reforms (2010 and 2012), since the unilateral initiative of the Government, have made the situation worse.
\end{abstract}

Key-words: unions, social dialogue, employment, labour market reform.

Artigo recebido em 03 de setembro de 2016 e aprovado em 11 de novembro de 2016 .

1 Doutor em Direito Econômico. Professor da Universidad de Sevilla, Sevilla, Espanha. 


\section{INTRODUCCIÓN}

Este documento de trabajo presenta el estudio de caso de los sindicatos españoles más representativos como agentes de cambio y regulación de los mercados de trabajo a través del diálogo social entre 1996 y 2013. Este caso encaja en la evolución registrada en Europa occidental, en la que se parte de una posición proclive a los acuerdos hasta llegar, a partir de 2009-2010, a una ruptura que puede parecer definitiva.

Centrado en el caso de España y sus sindicatos más representativos, Unión General de Trabajadores (UGT) y Comisiones Obreras (CC OO), el estudio pretende determinar las etapas de diálogo social y confrontación registradas, examinar el tipo de acuerdos sociales suscritos, así como sus incentivos y medidas adoptadas, y los efectos que han tenido sobre el mercado de trabajo. En un segundo nivel de análisis, se pretende determinar el impacto sobre la representatividad y la influencia económica y social obtenido por las organizaciones de trabajadores en su participación en estos pactos.

Para ello, se parte de un estado de la cuestión y marco teórico en el que se introduce la situación y evolución general del sindicalismo en Europa occidental y se explica el concepto de "corporatismo competitivo". Los acuerdos sociales celebrados a partir de la década de 1990 guardan en común un objetivo general de conseguir mayor competitividad para el país a base de introducir flexibilidad y desregular los marcos normativos del trabajo. Una estrategia apoyada por la Unión Europea (UE).

El siguiente epígrafe trata de la metodología adoptada y la aplicación al caso de España, con una explicación del enfoque adoptado, los indicadores analizados y las preguntas fundamentales que han guiado la investigación.

A partir de ahí, se abre un apartado en el que se delimita las etapas de diálogo social y confrontación en España, se analizan las reformas fruto de los pactos sociales, se evalúa el impacto sobre el mercado de trabajo en perspectiva comparada y, finalmente, el efecto sobre los sindicatos. En último término se examina la ruptura del diálogo social y las dos últimas reformas laborales (2010 y 2012) realizadas por diferentes gobiernos, pero con una práctica unilateral y alejada del consenso social.

El estudio realizado ha permitido concluir los escasos resultados logrados por las reformas pactadas en la concertación social competitiva para mejorar la eficacia y calidad del mercado de trabajo español. Tal insuficiencia, que no mejoró sustancialmente la posición de partida de los indicadores españoles frente a la media de los países de su entorno, ha permanecido invariable e incluso se ha ensanchado con las dos últimas reformas acometidas en 2010 y 2012.

Del mismo modo, la larga etapa de acuerdos sociales no parece haber fortalecido la base de las organizaciones sindicales españolas mayoritarias, que no acumularon la suficiente fuerza como para oponerse con éxito a una política que, desde la primavera de 2010 , consideran regresiva y dañina social y laboralmente.

\section{ESTADO DE LA CUESTIÓN Y MARCO TEÓRICO}


En este epígrafe se abordará, en primer lugar, un análisis del sindicalismo de Europa occidental y, posteriormente, se definirá claramente el tipo de concertación social desarrollado en la cronología propuesta.

En Europa, frente al tipo escandinavo de alta afiliación y de intermediación directa entre sindicatos y empresariado, se encuentran los modelos anglosajón, continental y meridional, que cuentan con baja afiliación relativa, sobre todo este último, y una mayor representación y cobertura de la negociación colectiva. ${ }^{1}$ España se encuadra dentro del modelo meridional, con tasas de afiliación (Tabla 1) y representación sindical homologables en este entorno. ${ }^{2}$

La evolución de la afiliación muestra un proceso de debilitamiento progresivo general. En Europa occidental la proporción de trabajadores afiliados no había sido tan baja desde $1950{ }^{3}$ Solamente se oponen a esta tendencia general los sindicatos de los países nórdicos. La razón fundamental comúnmente considerada para explicar esta diferencia es el denominado "sistema Gante", que ofrece poderosos incentivos a la afiliación, pues es el sindicato el dispensador directo de determinados seguros sociales, incluso del de desempleo, y es necesaria la afiliación para su acceso. $^{4}$

TABLA 1. DENSIDAD SINDICAL EN EUROPA OCCIDENTAL, TASA DE TRABAJADORES AFILIADOS, 1980-2011

\begin{tabular}{lllllllll}
\hline País/fecha & 1980 & 1985 & 1990 & 1995 & 2000 & 2004 & 2007 & 2011 \\
\hline Austria & 56,7 & 51,6 & 46,9 & 41,1 & 36,6 & 34,1 & 29,9 & 27,8 \\
Bélgica & 54,1 & 52,4 & 53,9 & 55,7 & 49,5 & 53,1 & 52,9 & 50,4 \\
Dinamarca & 78,6 & 78,2 & 75,3 & 77 & 74,2 & 71,7 & 69,1 & 68,5 \\
Finlandia & 69,4 & 69,1 & 72,5 & 80,4 & 75 & 73,3 & 70,3 & 70 \\
Francia & 18,3 & 13,6 & 10 & 8,8 & 8 & 7,8 & 7,6 & $7,9^{*}$ \\
Alemania & 34,9 & 34,7 & 31,2 & 29,2 & 24,6 & 22,2 & 19,9 & 18 \\
Grecia & 39 & 37,5 & 34,1 & 31,3 & 26,5 & 24,5 & 24,5 & 25,4 \\
Irlanda & 58,4 & 55,4 & 52,2 & 48,1 & 37,2 & 34,8 & 32,1 & 36,1 \\
Italia & 49,6 & 42,5 & 38,8 & 38,1 & 34,8 & 34,1 & 33,5 & 35,2 \\
Holanda & 34,8 & 28 & 24,3 & 25,2 & 22,6 & 21,6 & 20,2 & 19 \\
Noruega & 58,3 & 57,5 & 58,5 & 57,3 & 54,4 & 55 & 53,7 & 54,6 \\
Portugal & 54,8 & 44,6 & 28 & 25,4 & 21,6 & 21,4 & 20,8 & $19,3^{*}$ \\
España & 18,7 & 10,2 & 12,5 & 16,3 & 16,7 & 15,3 & 14,7 & $15,6^{*}$ \\
\hline
\end{tabular}

${ }^{1}$ BENEYTO, Pere J. "Panorama actual de la afiliación sindical", en Observatorio Confederal de Afiliación de CCOO, $\mathrm{n}^{\circ}$ 1, diciembre, 2009, pp. 2-3. Disponible en http://www.1mayo.ccoo.es consultado $14 / 02 / 2013$

${ }^{2}$ Los sindicatos españoles, en general, se integran dentro del tipo mediterráneo europeo de pluralidad confederal que divide a los trabajadores entre dos, tres e incluso más centrales sindicales en función de orientaciones político-ideológica.

${ }^{3}$ WADDINGTON, Jeremy. "Afiliación sindical en Europa. La magnitud del problema y la variedad de las respuestas sindicales", Documentos de trabajo para la Universidad de verano de la CES/ETUI-REHS de los dirigentes sindicales europeos, 2005. Disponible en http://www.ugt.es/internacional/universidadces/univeranocesafiliacion.pdf consultado 11/10/2012

${ }^{4}$ SCHMITT, John y MITUKIEWICZ, Alexandra. "Politics matter: changes in unionization rates in rich countries, 1960-2010”, Industrial Relations Journal, vol. 43(3), 2012, pp. 260-280. 


\begin{tabular}{|c|c|c|c|c|c|c|c|c|}
\hline Suecia & 78 & 81,3 & 80,9 & 86,6 & 80,1 & 76,9 & 71 & 68,9 \\
\hline Reino Unido & 51,7 & 46 & 39,7 & 34,4 & 30,1 & 28,3 & 27,4 & $27,1^{*}$ \\
\hline
\end{tabular}

Resulta claro que, con independencia del grado de participación en los procesos nacionales de concertación social, los sindicatos se han desenvuelto en un contexto claramente desfavorable en los últimos cuarenta años.

Al igual que se han reducido las tasas de afiliación, desde la década de 1990 ha disminuido la cobertura de la negociación colectiva, y los diferentes sistemas de negociación han tendido a descentralizarse hacia el nivel de empresa, en detrimento del sector o de acuerdos intersectoriales. Una tendencia que coincide con la merma de la capacidad de los sindicatos para intervenir en los cambios normativos a nivel nacional.

Tabla 2. TASA de Cobertura de la Negociación Colectiva en EuROPa occidental, 1993-2010

\begin{tabular}{llllll}
\hline País / fecha & 1993 & 1995 & 2004 & 2008 & 2010 \\
\hline Alemania & $73,1^{*}$ & 76,0 & 65,8 & 63,9 & 61,1 \\
Austria & $98^{*}$ & $98^{*}$ & $99^{*}$ & $99^{*}$ & 99 \\
Bélgica & $96^{*}$ & $96^{*}$ & $96^{*}$ & 96 & 96 \\
Dinamarca & $84^{*}$ & 84 & 85 & $85^{*}$ & $\mathrm{ND}$ \\
España & $77^{*}$ & $83^{*}$ & 77,4 & 80,2 & 73,2 \\
Finlandia & $85^{*}$ & $85^{\star}$ & 88,3 & $89,5^{\star}$ & $\mathrm{ND}$ \\
Francia & $92^{*}$ & $\mathrm{ND}$ & $92^{*}$ & 92 & $\mathrm{ND}$ \\
Grecia & $65^{*}$ & 65 & $65^{\star}$ & 65 & $\mathrm{ND}$ \\
Irlanda & $\mathrm{ND}$ & $\mathrm{ND}$ & $41,9^{*}$ & $\mathrm{ND}$ & 42,2 \\
Italia & $85^{*}$ & 85 & 85 & $\mathrm{ND}$ & 85 \\
Luxemburgo & $60^{*}$ & $60^{*}$ & $58^{*}$ & 58 & $\mathrm{ND}$ \\
Países Bajos & $81,1^{*}$ & $83,4^{*}$ & $84,7^{*}$ & 85 & 84,3 \\
Portugal & 94,7 & $94,7^{*}$ & $\mathrm{ND}$ & 90 & $90^{*}$ \\
Reino Unido & $40^{*}$ & 36 & 34,7 & 33,6 & 30,8 \\
Suecia & $89^{*}$ & 94 & $94^{*}$ & 91 & 91 \\
\hline
\end{tabular}

$\left(^{*}\right)$ Las cifras que corresponden a años inmediatamente anteriores 0 posteriores a la fecha indicada.

Fuente: J. Visser. Data Base on Institutional Characteristics of Trade Unions, Wage Setting, State Intervention and Social Pacts, 1960-2011 (ICTWSS), version 4.0. http://www.uva-aias.net

El estancamiento económico, la caída de beneficios empresariales y las elevadas tasas de desempleo iniciadas en la década de 1970, las políticas centradas en la oferta y la desregulación económica triunfantes a partir de la década de 1980, las nuevas exigencias competitivas, la globalización progresiva de los mercados, han impuesto una producción de 
bienes y servicios centrada en la flexibilidad, la reducción de costes y la innovación permanentes. Los cambios normativos introducidos para ello han significado la pérdida de poder de los sindicatos y el refuerzo de la autoridad empresarial para implementar cambios unilaterales. ${ }^{5} \mathrm{De}$ igual modo, se ha consolidado una visión del mercado como mecanismo de regulación autónomo de las relaciones entre los individuos, y el beneficio empresarial como origen del crecimiento económico y del empleo.

En tal contexto, el papel jugado por los sindicatos se ha reducido al mismo tiempo que la capacidad de regulación del Estado. El capitalismo transnacional excede el marco regulatorio de los países y, en muchas ocasiones, hace poco operativos los acuerdos alcanzados. Esto no quiere decir que los sistemas de relaciones laborales y sus instituciones hayan desaparecido, pero se ha impuesto una dinámica que supera el control ejercido por las tradicionales formas de representación y negociación, muy apegadas al marco nacional. En Europa, en la actualidad, los sindicatos están impelidos a abordar un triple escenario de trabajo, el nacional, en el que habría de incluirse lo local-regional, el delimitado por la Unión Europea y el mundial. ${ }^{6}$ No hace falta decir que en los dos últimos se han mostrado notablemente inoperantes.

La concertación social que se ha afirmado en Europa occidental cada vez con mayor claridad desde finales de la década de 1980 ha sido notablemente diferente a los acuerdos generales de renta y de políticas centradas en la demanda desarrollados en Europa en las décadas de 1960 y 1970, que coincidieron con el periodo de mayor afiliación y poder sindical. ${ }^{7}$

Se han modificado estructura, materias e incentivos de negociación. Los pactos sociales, en los países que han tenido lugar, buscaron la generación y el mantenimiento de puestos de trabajo y del Estado del Bienestar, pero a costa de limitar salarios y prestaciones sociales, pues el estímulo del empleo derivaba del aumento de la competitividad del tejido empresarial. Cada uno de los países ha pretendido ganar competitividad frente a otros, una estrategia en la que se han insertado los sindicatos a través de los acuerdos suscritos. Un modelo que, a pesar de las intenciones de las organizaciones sindicales de contribuir a la generación de empleo, ha subrayado las insolidaridades y acentuado la competencia entre trabajadores de diferentes países. ${ }^{8}$ Esta nueva concertación ha sido denominada como "competitiva", "corporatismo competitivo", ${ }^{9} \mathrm{O}$ "del lado de la oferta" (supply side corporatism).$^{10}$

5 BAÑOS DÍEZ, Daniel y PÉREZ CUERNO, José Manuel. "Globalización, flexibilidad y neocorporativismo", Revista Universitaria de Ciencias del Trabajo, $\mathrm{n}^{\circ}$ 6, 2005, pp. 772-774, 780-781.

${ }^{6}$ MIGUÉLEZ, Fausto. "Presentación". Cuaderno de Relaciones Laborales, Vol. 26 (1), 2008, pp. 9-16.

${ }^{7}$ REGINI, Marino. "Tripartite Concertation and Varieties of Capitalism", European Journal of Industrial Relations, vol. 9, n 3, 2003, pp. 251-263.

8 ANTENAS COLLDERREMAN, Josep M. "Los sindicatos ante la globalización. ¿Hacia qué nuevas formas de solidaridad internacional?”. Cuadernos de Relaciones Laborales, Vol 26, No 1, 2008, pp. 35-55.

${ }^{9}$ RHODES, Martin. "Globalization, Labour Markets and Welfare States: A Future of 'Competitive Corporatism'?". RHODES, M., MÉNY, Y. (Eds.), The Future of European Welfare: A New Social Contract?, London, Macmillan, 1998, pp. 178-203, y RHODES, Martin (2000). "The Polítical Economy of Social Pacts: 'Competitive Corporatism' and European Welfare Reform”. PIERSON, P. (Ed.), The new politics of the Welfare State, Oxford, University Press, 2000, pp. 165-196.

${ }^{10}$ La noción "corporatismo del lado de la oferta" en Traxler F. (2001) 'Die Metamorphosen des Korporatismus: vom klassischen zumschlanken Muster', Politische Vierteljahresschrift 42: 590-623, cit. SIEGEL, Nico A. "Social Pacts Revisited: 'Competitive Concertation' and Complex Causality in Negotiated Welfare State Reforms". European Journal of Industrial Relations, vol. 11, n 1, 2005, pp. 107 126. 
La denominada "concertación social competitiva" ha buscado el acuerdo social para impulsar fórmulas de desregulación y flexibilidad menos radicales y lesivas de los modelos sociales, pero también más consensuadas y con menor coste en términos de conflictividad sociolaboral. Los acuerdos se han fragmentado y descentralizado respecto de los basados en la demanda. ${ }^{11}$

Esta segmentación de lo negociado ha permitido que los sindicatos hayan podido sumarse a acuerdos concretos sobre políticas parciales que, aunque controvertidos, no apoyaban globalmente las políticas generales de liberalización, del todo inasumibles e impresentables ante sus bases.

De un modo muy apreciable, a partir de la década de 1990, los "pactos competitivos" se extendieron al calor de profundas reformas institucionales y cambios macroeconómicos que se pretendía acometer. Baste indicar que, en 2003, todos los países de Europa occidental desarrollaron acuerdos de este tipo menos Dinamarca, Italia, Francia y Reino Unido. ${ }^{12}$

El proceso de integración económica, conocido como Unión Económica y Monetaria (UEM), exigió a los Estados Miembros una serie de reformas que implicaron la introducción de cierta disciplina "ortodoxa" en las cuentas públicas y medidas de flexibilidad y desregulación. Se impusieron topes concretos a la inflación, al déficit público y a la deuda pública. Estas medidas exigieron reformas en profundidad a los estados miembros que, en muchos casos, acometieron a través de nuevos pactos sociales. Este factor institucional y la mayor exposición a la competencia internacional (globalización) han sido fundamentales para la consolidación del "corporatismo competitivo". Los gobiernos, particularmente los más débiles, buscaron amplios consensos para emprender los cambios requeridos. En Italia, Irlanda, Grecia, Portugal e inicialmente Países Bajos los "ortodoxos" criterios de convergencia económica del Tratado de Maastrich se alcanzaron mediante fórmulas de acuerdo tripartito. ${ }^{13}$ En España y en Irlanda fueron las reformas de los sistemas de bienestar, en clave restrictiva, los que se abordaron mediante acuerdos tripartitos.

El problema más importante de los países de Europa occidental era el paro, sobre todo en sus regiones relativamente más atrasadas y en colectivos como mujeres, jóvenes y discapacitados. Así lo reconocía la Unión Europea en 1997 con ocasión del Consejo de Luxemburgo y la Estrategia Europea de Empleo para todos los Estados Miembros. El programa comunitario para luchar contra el desempleo ha encajado perfectamente dentro del paradigma de acuerdos competitivos o del lado de la oferta: la mejora de la "empleabilidad" a través de la formación y las prácticas laborales; el estímulo del espíritu empresarial mediante exenciones fiscales, sobre todo a pymes; la promoción de la flexibilidad y la adaptabilidad de la organización

\footnotetext{
${ }^{11} \mathrm{La}$ descentralización se ha producido hacia las regiones con la suscripción de acuerdos por la competitividad y el empleo de ese territorio.

12 BACCARO, Lucio y SIMONI, Marco. "Policy Concertation in Europe Understanding Government Choice". Comparative Political Studies, vol. 41, n 10, 2008, p. 1326. Reino Unido se ha mantenido invariablemente al margen de los acuerdos corporatistas desde del triunfo de Margaret Thatcher.

13 REGINI, Marino. "I dilemmi del sindicato del 2000: più rappresentanza per avere influenza o viceversa?", Quaderni di Rassegna Sindícale, nº Speciale Congreso CGIL, 2002, p. 258.
} 
del trabajo, y finalmente la igualdad de oportunidades para facilitar el acceso de mujeres y discapacitados. ${ }^{14}$

La crisis económica iniciada en los últimos meses de 2007, sin embargo, ha coincidido con la ruptura del diálogo social en los países de Europa occidental. En principio, podía pensarse que las dificultades impuestas por los problemas de crecimiento económico y alto desempleo serían estimularían la suscripción de pactos.

En los primeros meses de retroceso económico, se alzaron voces que solicitaron un cierto regreso a las políticas keynesianas. A fin de cuentas, se venían aplicando políticas de oferta, competitividad y desregulación desde la década de 1980, y de hecho estas políticas estaban en vigor cuando se produjo se inició la crisis. Los sindicatos, por supuesto, aspiraron al regreso de políticas centradas en la demanda que podrían dirigir, como en otro tiempo, hacia reforzar los sistemas sociales y mejorar el empleo. En sintonía con esta pretensión la Confederación Europea de Sindicatos ha pedido, de forma reiterada, un gigantesco plan de inversiones respaldado por el Banco Central Europeo (BCE).

Sin embargo, desde 2009 las autoridades de la UE y los gobiernos de los Estados Miembros comenzaron a decantarse por políticas de ajuste, recortes sociales, desregulaciones de los mercados de trabajo, rigor fiscal. ${ }^{15}$ Se intensificaron, en definitiva, las políticas aplicadas en los dos decenios anteriores, pero en un contexto marcado por alto desempleo y graves desequilibrios de los presupuestos públicos. La búsqueda de mayor competitividad en las empresas y, por ende, en los países que aplicaban estas políticas se tornaba así como una política de ajuste a gran escala basado en devaluaciones internas.

Los sindicatos, defraudados en sus expectativas, no han podido suscribir estas políticas. Pese a que habían formado parte del consenso competitivo, ya no tenían margen alguno de negociación.

No era presentable, de ningún modo, continuar en acuerdos que imponían un ajuste general en el que los principales damnificados eran los trabajadores $y$, sobre todo, los desempleados. Sin que la extensa tradición de acuerdos constituyera un problema esencial, los sindicatos de Francia, Irlanda (después de veinte años de concertación), Italia y Finlandia convocaron huelgas en el primer semestre de 2009.

La vuelta al disenso por parte de los sindicatos rompió el diálogo social. En Irlanda en 2009 el diálogo social se truncó por una bajada de salario de trabajadores públicos y recorte de las pensiones. En España las negociaciones llegaron a un punto muerto en 2009, sólo se alcanzó un acuerdo de pensiones en 2011, que se esperaba fuera la antesala de un gran acuerdo social contra la crisis que nunca llegó. El retraso de la edad de jubilación en Finlandia supuso una

\footnotetext{
${ }^{14}$ LÉONARD, Evelyne. "Governance and Concerted Regulation of Employment in Europe", European Journal of Industrial Relations, vol. 11, n 3 , 2005, p. 308. ROCHA, Fernando y ARAGÓN, Jorge. Mecanismos de evaluación de los pactos de empleo en las comunidades autónomas: situación y experiencias. Madrid: Fundación $1^{\circ}$ de Mayo, 2001, p. 4.

${ }^{15} \mathrm{El} \mathrm{BCE}$ ha insistido con reiteración en que la prioridad son la estabilidad de precios y reducir los costos de mano de obra, la OCDE, en 2009, llamó a un esfuerzo continuo de liberalización del mercado en la Unión Europea. HYMAN, Richard. "Social dialogue and industrial relations during the economic crisis: Innovative practices or business as usual?", Working Paper No. 11, Industrial and Employment Relations Department, Internacional Labour Organization, 2010, p. 3.
} 
huelga general. En Portugal las confederaciones sindicales más importantes reclamaron sin éxito medidas urgentes contra el desempleo. En Holanda la confederación sindical no transigió con el aumento de la edad de jubilación, al que se opuso. La excepción se encuentra en Bélgica, país en el que se acordaron medidas de apoyo a los trabajadores para soportar la situación de crisis.

En realidad, la actual crisis ha revelado que una articulación de pactos por países, en el actual contexto de globalización, resulta poco operativa. Los acuerdos nacionales deben incardinarse en acuerdos de rango superior a nivel de la UE. Una perspectiva que está lejos de ser efectiva. De la incapacidad del diálogo social europeo para afrontar la crisis se puede inferir su escasa calidad.

Tal como indicaba Schmitter en 1991, la actual crisis económica parece mostrar que las prácticas corporatistas han funcionado mucho mejor, y por tanto con más credibilidad, en las fases expansivas del ciclo económico. Cuando hay suficientes recursos para compensar a los sindicatos a cambio de estabilizar y ajustar la economía. ${ }^{16}$

\section{METODOLOGÍA}

Para alcanzar los objetivos planteados en el primer epígrafe, se plantea un estudio de de la evolución del diálogo social en España desde 1996 a la actualidad, con especial atención a los cambios operados sobre el mercado de trabajo y su impacto sobre la evolución de las tasas de desempleo.

No se oculta la dificultad de aislar las diferentes reformas del mercado de trabajo, con la inclusión de los cambios sobre materia de acuerdos colectivos, de otros factores que explican la evolución del paro en un territorio determinado. Sin embargo, un análisis cualitativo de su evolución, en perspectiva comparada, puede indicar si las transformaciones realizadas cambian sustancialmente. Datos de Eurostat y el Instituto Nacional de Estadística (INE).

En relación a esto, la pregunta fundamental que trataremos de abordar se centra en dilucidar hasta qué punto, en España, las políticas desarrolladas en materia de empleo, con y sin pactos sociales, han contribuido efectivamente a lograr un mejor desempeño del mercado de trabajo.

Además de la evolución del mercado de trabajo y sus resultados en términos de eficacia y calidad, resulta de interés aproximar el impacto de la participación de los sindicatos más representativos en el diálogo social. Se tendrá en cuenta para ello la representación sindical (elecciones), la cobertura de la negociación colectiva, la conflictividad laboral y el nivel de conocimiento de la actividad sindical. Resultados obtenidos a partir de datos disponibles en Eurostat, los trabajos de Jelle Visser, ${ }^{17}$ el Instituto Nacional de Estadísticas, Ministerio de Empleo y Seguridad Social o los propios sindicatos.

La participación de los sindicatos en estos tipos de pactos sociales, centrados en la desregulación y la flexibilidad, ha planteado cuestiones que es preciso resolver. Una participación, en principio, en contra de la lógica de las organizaciones sindicales, interesadas

\footnotetext{
${ }^{16}$ SCHMITTER, Philippe C. "La concertación social en perspectiva comparada", ESPINA, A. (Comp.), Concertación social, neocorporatismo y democracia, Madrid, Ministerio de Trabajo y Seguridad Social, 1991, p. 77.

${ }^{17}$ Data Base on Institutional Characteristics of Trade Unions, Wage Setting, State Intervention and Social Pacts, 1960-2011 (ICTWSS), version 4.0. http://www.uva-aias.net
} 
en introducir rigidez y asentar su posición negociadora. Una de las posibles respuestas que se intentará verificar es la propia debilidad de partida de los sindicatos y los poderosos incentivos, en términos de financiación e influencia política, que los gobiernos le han ofrecido para insertarse en estos pactos.

\section{LOS SINDICATOS MÁS REPRESENTATIVOS ESPAÑOLES}

La victoria del Partido Popular (PP) en las elecciones legislativas de 1996 coincidió con el inicio de la recuperación económica a nivel mundial. El nuevo Gobierno conservador, al igual que los últimos ejecutivos socialistas, no disponía de mayoría absoluta y hubo de alcanzar pactos estables de legislatura con otros grupos políticos nacionalistas de centro-derecha. La relativa debilidad del Gobierno y los sindicatos mayoritarios, ${ }^{18}$ la buena disposición de la Confederación Española de Organizaciones Empresariales (CEOE) hacia las reformas que se estaban acometiendo, la necesidad de consenso social para dejar atrás la crisis iniciada en 1992, la influencia europea favorable hacia los acuerdos de concertación, la fragmentación de lo acordado en mesas separadas de negociación y el inicio de la recuperación económica permitieron que se rehabilitaran los pactos sociales. A partir de entonces, se impuso un crecimiento basado en las infraestructuras y la construcción que logró rebajar considerablemente las tasas de paro (por debajo del $10 \%$ en 2007), pero no las de temporalidad.

En sintonía con otros sindicatos europeos, los españoles se aprestaron a participar en acuerdos que salvaguardaran los derechos sociales y laborales mínimos en medio de las "reformas necesarias". Esta "realismo" ha comportado la aceptación de ciertos criterios empresariales, sobre todo relativos a la creación de empleo. ${ }^{19}$

Esta etapa dejó una serie de acuerdos sobre el sistema de pensiones ("Pacto de Toledo"), Acuerdo Extrajudicial de Resolución de Conflictos (1996), para la Estabilidad en el Empleo y sobre Negociación Colectiva (1997). Entre 1998 y 2004 se suscribieron los acuerdos tripartitos sobre Formación Continua (2000), sobre la Solución Extrajudicial de Conflictos Laborales (2001) y de Negociación Colectiva (2002), ${ }^{20}$ aunque también se produjeron disrupciones notables que desembocaron en enfrentamiento, como el ocurrido con ocasión de la propuesta de reforma laboral de primavera de 2002 y la consiguiente huelga general de 20 de junio. La huelga contó con el suficiente apoyo como para que el Gobierno retirara en su práctica totalidad la reforma presentada y dimitiera el ministro de Trabajo. En cambio, entraron en vigor dos medidas que supusieron recortes de derechos para los trabajadores, la ampliación del denominado "empleo adecuado" que debían aceptar los perceptores de prestaciones por desempleo, y el despido improcedente sin necesidad de justificación ni consecuencias judiciales para el empresario, siempre que abonara la indemnización correspondiente. Los sindicatos,

\footnotetext{
${ }^{18}$ La posición de partida de los sindicatos en 1996 era de notable debilidad. La estrategia de confrontación frente los últimos ejecutivos socialistas y otros errores les hicieron perder en las elecciones sindicales de 1994-1995 más de 40.000 delegados con respecto al periodo anterior

${ }^{19}$ SANTOS ORTEGA, Antonio. "La invasión de la ideología empresarial en los márgenes del mercado de trabajo: inseguridad laboral, paro e inserción”. Cuaderno de Relaciones Laborales, Vol. 21, n 1, 2003, pp. 107-128.

${ }^{20}$ PÉREZ INFANTE, José I. “La concertación y el diálogo social en España: 1977-2007”, Revista del Ministerio de Trabajo e Inmigración, no 81, 2009, pp. 62-63.
} 
como compensación del Ejecutivo, obtuvieron un reforzamiento institucional al asumir un mayor protagonismo (y financiación correspondiente) en la formación continua, la supervisión de la contratación y la seguridad en el trabajo.

TABLA 3. DESEMPLEO EN EUROPA OCCIDENTAL

\begin{tabular}{llllllllll}
\hline & 1996 & 2000 & 2004 & 2007 & 2008 & 2009 & 2011 & 2012 & 2013 \\
\hline Unión Europea 28 & $\mathrm{ND}$ & 8,9 & 9,3 & 7,2 & 7,0 & 8,9 & 9,6 & 10,4 & 10,8 \\
$\begin{array}{l}\text { Unión Europea 15 } \\
\text { Alemania (RFA }\end{array}$ & 10,3 & 7,9 & 8,3 & 7,1 & 7,2 & 9,1 & 9,6 & 10,6 & 11,0 \\
1990) & & & & & & & & & \\
Austria & 8,9 & 8,0 & 10,5 & 8,7 & 7,5 & 7,8 & 5,9 & 5,5 & 5,3 \\
Bélgica & 4,3 & 3,6 & 4,9 & 4,4 & 3,8 & 4,8 & 4,2 & 4,3 & 4,9 \\
Dinamarca & 9,5 & 6,9 & 8,4 & 7,5 & 7,0 & 7,9 & 7,2 & 7,6 & 8,4 \\
España & 6,3 & 4,3 & 5,5 & 3,8 & 3,5 & 6,0 & 7,6 & 7,5 & 7,0 \\
Finlandia & 19,9 & 11,9 & 11,0 & 8,2 & 11,3 & 17,9 & 21,4 & 24,8 & 26,1 \\
Francia & 14,6 & 9,8 & 8,8 & 6,9 & 6,4 & 8,2 & 7,8 & 7,7 & 8,2 \\
Grecia & 11,0 & 9,0 & 8,9 & 8,0 & 7,5 & 9,1 & 9,2 & 9,8 & 10,3 \\
Holanda & $\mathrm{ND}$ & 11,2 & 10,8 & 8,5 & 7,9 & 9,7 & 17,9 & 24,3 & 27,3 \\
Irlanda & 6,4 & 3,1 & 5,1 & 3,6 & 3,1 & 3,7 & 4,4 & 5,3 & 6,7 \\
Italia & 11,7 & 4,2 & 4,5 & 4,7 & 6,4 & 12,0 & 14,7 & 14,7 & 13,1 \\
Luxemburgo & 11,2 & 10,0 & 8,0 & 6,1 & 6,7 & 7,8 & 8,4 & 10,7 & 12,2 \\
Noruega & 2,9 & 2,2 & 5,0 & 4,2 & 4,9 & 5,1 & 4,8 & 5,1 & 5,8 \\
Portugal & 4,7 & 3,2 & 4,3 & 2,5 & 2,5 & 3,2 & 3,3 & 3,2 & 3,5 \\
Reino Unido & 7,2 & 4,5 & 7,5 & 8,9 & 8,5 & 10,6 & 12,9 & 15,8 & 16,4 \\
Suecia & 7,9 & 5,4 & 4,7 & 5,3 & 5,6 & 7,6 & 8,0 & 7,9 & 7,5 \\
\hline \multicolumn{1}{l}{ Fuente: Eurostat } & 9,6 & 5,6 & 7,4 & 6,1 & 6,2 & 8,3 & 7,8 & 8,0 & 8,0 \\
\hline
\end{tabular}

Fuente: Eurostat

TABLA 4. PorCENTAJE DE EMPLEADOS TEMPORALES SOBRE EL TOTAL DE TRABAJADORES

\begin{tabular}{|c|c|c|c|c|c|c|c|c|c|}
\hline & 1996 & 2000 & 2004 & 2007 & 2008 & 2009 & 2011 & 2012 & 2013 \\
\hline Unión Europea 28 & ND & ND & 13,2 & 14,6 & 14,1 & 13,5 & 14,0 & 13,7 & 13,8 \\
\hline Unión Europea15 & 11,8 & 13,6 & 13,5 & 14,9 & 14,5 & 13,8 & 14,2 & 13,8 & 13,8 \\
\hline hasta 1990) & 11,1 & 12,8 & 12,5 & 14,7 & 14,8 & 14,6 & 14,8 & 13,9 & 13,5 \\
\hline Austria & 8,0 & 8,0 & 9,5 & 8,9 & 9,0 & 9,1 & 9,6 & 9,3 & 9,2 \\
\hline Bélgica & 5,9 & 9,0 & 8,7 & 8,6 & 8,3 & 8,2 & 8,9 & 8,1 & 8,1 \\
\hline España & 33,8 & 32,4 & 32,1 & 31,7 & 29,3 & 25,5 & 25,4 & 23,7 & 23,4 \\
\hline Dinamarca & 11,3 & 10,2 & 9,8 & 9,0 & 8,5 & 8,7 & 8,9 & 8,6 & 8,8 \\
\hline Finlandia & 17,3 & 17,7 & 17,1 & 15,9 & 14,9 & 14,5 & 15,5 & 15,5 & 15,3 \\
\hline Francia & 12,5 & 15,4 & 12,8 & 15,0 & 14,8 & 14,3 & 15,1 & 15,0 & 16,4 \\
\hline Grecia & 11,0 & 13,8 & 12,4 & 10,9 & 11,5 & 12,1 & 11,6 & 10,0 & 10,0 \\
\hline Holanda & 11,9 & 13,8 & 14,4 & 17,9 & 17,9 & 18,0 & 18,2 & 19,3 & 20,3 \\
\hline Irlanda & 9,2 & 5,3 & 3,4 & 8,0 & 8,4 & 8,8 & 10,2 & 10,1 & 10,0 \\
\hline Italia & 7,4 & 10,1 & 11,9 & 13,2 & 13,3 & 12,5 & 13,4 & 13,8 & 13,2 \\
\hline Luxemburgo & 2,6 & 3,4 & 4,8 & 6,8 & 6,2 & 7,2 & 7,1 & 7,6 & 7,0 \\
\hline Noruega & 13,2 & 9,7 & 10,2 & 9,5 & 9,0 & 8,1 & 8,0 & 8,5 & 8,4 \\
\hline
\end{tabular}




\begin{tabular}{llllllllll}
\hline \hline Portugal & 10,7 & 19,8 & 19,9 & 22,4 & 22,9 & 22,0 & 22,2 & 20,7 & 21,5 \\
Reino Unido & 7,0 & 6,6 & 5,6 & 5,7 & 5,3 & 5,5 & 6,0 & 6,2 & 6,1 \\
Suecia & 11,5 & 14,3 & 15,5 & 17,2 & 15,8 & 14,9 & 16,5 & 15,9 & 16,3 \\
\hline
\end{tabular}

Fuente: Eurostat

En 2004, con un nuevo ejecutivo socialista, se impulsó el diálogo social. Sin embargo, no se logró un acuerdo de reforma del mercado de trabajo hasta 2006 que, si bien limitaba la concatenación de contratos a término para reducir la temporalidad, en realidad suponía consolidar y extender la flexibilidad alcanzada por el anterior gobierno de centro-derecha en la salida y entrada de trabajadores en las empresas. Los acuerdos, a partir de ahí, se extendieron en materias como dependencia, igualdad de la mujer y reforma de la seguridad social, entre otras. Este periodo de concertación coincidió con un periodo de expansión económica, en el que se generó crecimiento económico y empleo, si bien con los matices que señalan las tablas 3 y 4.

Para los sindicatos más representativos, esta etapa se saldó con un progreso ininterrumpido en la afiliación y en la audiencia electoral obtenida en las elecciones a representantes unitarios de los trabajadores hasta 2008.

TABLA 5. REPRESENTACIÓN SINDICAL EN ESPAÑA, ELECCIONES A REPRESENTANTES UNITARIOS DE LOS TRABAJADORES 1995-2011

\begin{tabular}{lllllllllll}
\hline AÑO & DELEGS & CC OO & \multicolumn{3}{l}{ UGT } & \multicolumn{3}{c}{ OTROS } & \multicolumn{1}{c}{ NO AF } \\
\hline & & № & $\%$ & № & $\%$ & № & $\%$ & № & $\%$ \\
\hline 1995 & 204.586 & 77.348 & 37,8 & 71.112 & 34,7 & 49.495 & 24,2 & 6.631 & 3,2 \\
1999 & 260.285 & 98.440 & 37,8 & 96.770 & 37,2 & 57.006 & 21,9 & 8.969 & 3,1 \\
2003 & 280.396 & 109.431 & 39 & 102.930 & 36,7 & 60.584 & 21,6 & 7.471 & 2,7 \\
2007 & 310.231 & 121.556 & 39,2 & 114.269 & 36,8 & 68.190 & 22 & 6.216 & 2 \\
2011 & 307.011 & 116.331 & 37,9 & 109.913 & 35,8 & 74.877 & 24,4 & 5.890 & 1,9 \\
\hline
\end{tabular}

Fuente: JÓDAR, Pere. "Una breve panorámica de las elecciones sindicales de 2011, con apuntes de su evolución desde 2003", Anuario Sociolaboral de 2012, Madrid, Fundación 1ํ de Mayo Comisiones Obreras, 2013.

Un aumento de presencia social y en las empresas que coincidió con la extensión de su influencia política por la participación en los acuerdos sociales. Las razones de esta progresión se encuentran en las mejoras registradas en el mercado de trabajo en ese periodo y en la corrección de la pluralidad organizativa y la competencia intersindical, por la unidad de acción entre UGT y CC OO, y una menor dependencia de partidos políticos, que son elementos que debilitan la afiliación.

Por otro lado, según Visser o Regini, la influencia obtenida a través de la concertación social habría permitido una mayor penetración social y laboral a través de la ejecución de formación, planes de igualdad de género, prevención de riesgos laborales, etc. ${ }^{21}$ Sin embargo, el inicio de la crisis económica puso fin a la trayectoria ascendente de la afiliación, a la progresión en las elecciones a representantes de los trabajadores, así lo han reflejado también las Encuestas de Calidad de Vida en el Trabajo que señalan un retroceso a partir de 2008, pese a

\footnotetext{
${ }^{21}$ BENEYTO, Pere J. "El sindicalismo español en perspectiva europea: de la anomalía a la convergencia", Cuadernos de Relaciones Laborales. Vol. 26, n 1, 2008, pp. 68-73.
} 
que el clima de diálogo social fue estable -aunque sin pactos- hasta 2009 e incluso en los primeros años del siguiente año, pues no puede hablarse del inicio de su ruptura hasta mayo de 2010.

España cuenta con un modelo de representación sindical de altas tasas de cobertura en la negociación colectiva y baja densidad sindical, típico del área mediterránea europea, en el que cabe anotar a países como Francia o Italia. ${ }^{22}$ La negociación colectiva, de centralización intermedia con predominio del sector y la provincia como referentes de contratación, y coordinación media ${ }^{23}$ ha tenido una tasa de cobertura de los convenios singularmente alta, pero en los últimos años analizados (2008-2010) la evolución positiva registrada se ha frenado en seco y ha retrocedido 7 puntos porcentuales (Tabla 2).

Estos años (2009-2010) de diálogo social sin acuerdos, por tanto, comienzan a hacer retroceder con fuerza la densidad sindical, la audiencia electoral y la cobertura de la negociación colectiva.

En mayo de 2010 el Gobierno socialista español anunció, ante las presiones internacionales, particularmente de la UE, un estricto giro de su política económica hacia el ajuste presupuestario. Evidentemente, el diálogo social quedó roto por la desafección clara de los sindicatos que convocaron una huelga general el 29 de septiembre. ${ }^{24}$ El regreso a la confrontación ha coincidido con el creciente desprestigio social de las centrales sindicales mayoritarias y en la reducción de la tasa bruta de representación sindical en las empresas en cerca de dos puntos, situándose en el $47,4 \%$ en 2010 , aunque cerca de media, en 2008 , de los países mediterráneos (48\%), y de la UE-27 (50\%). ${ }^{25}$ Del mismo modo, la densidad sindical se ha mantenido baja, en torno al $15 \%{ }^{26}$

El regreso de la conflictividad con motivo de la ruptura del diálogo social no debe ocultar los escasos resultados obtenidos en su reducción los años precedentes. Entre 1980 y 2008 , periodo en el que la concertación social estuvo suspendida sólo nueve años, España fue el país europeo con más jornadas perdidas por huelga por cada 1.000 trabajadores.

\footnotetext{
22 Ibídem, p. 67.

${ }^{23}$ GLASSNER, Vera y POCHET, Philippe. "Why trade unions seek to coordinate wages and collective bargaining in the Eurozone: past developments and future prospects", Working Paper, 03, European Trade Union Institute, 2011, p. 25.

${ }^{24}$ Ello no fue óbice para en 2011 se lograse una reforma concertada del sistema de pensiones cuyo resultado consistió en retrasar la edad de jubilación, endurecer el acceso a la prestación máxima y recortar la renta media de los futuros jubilados. En la misma dinámica de ajuste y recorte de las prestaciones sociales de los pactos celebrados en los últimos años.

${ }^{25}$ BENEYTO, Pere J. "Panorama actual de la afiliación sindical", en Observatorio Confederal de Afiliación de CC OO, n 1 , diciembre, 2009, p. 3.

${ }^{26}$ Data Base on Institutional Characteristics of Trade Unions, Wage Setting, State Intervention and Social Pacts, 1960-2011 (ICTWSS), version 4.0. http://www.uva-aias.net.
} 
Gráfico. Promedio ANUAL de JoRnAdas PerdidAs PoR Huelga, 1980-2008

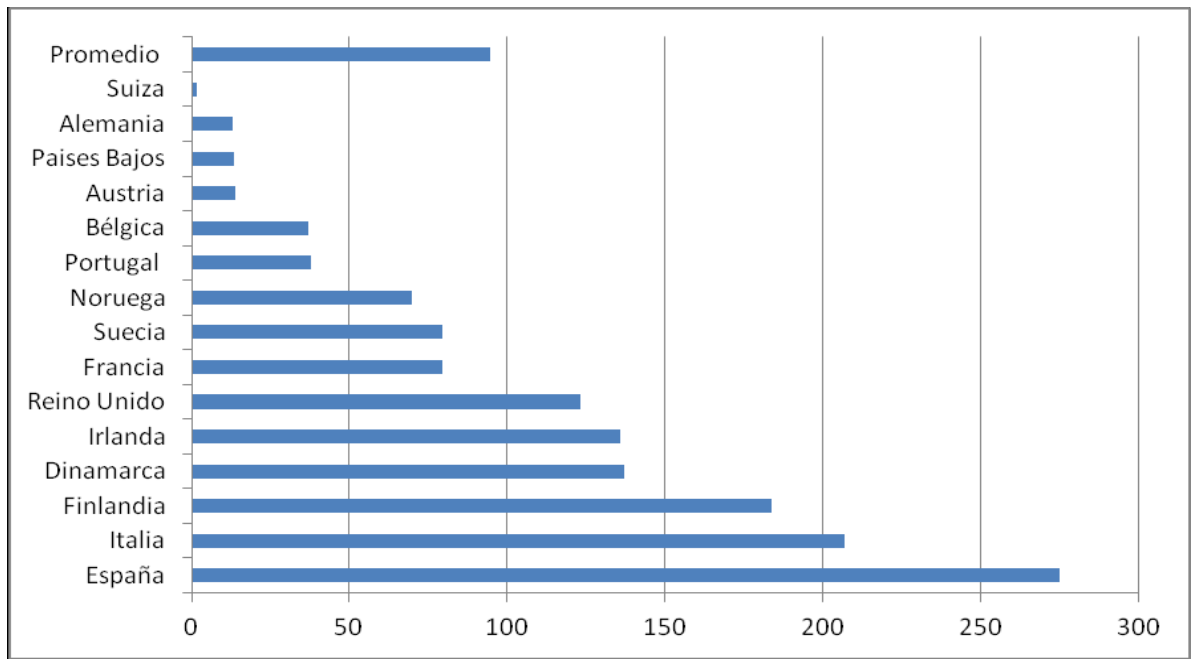

Fuente: LUQUE BALBONA, David. Las huelgas en España: intensidad, formas y determinantes, Tesis Doctoral, Departamento de Economía Aplicada de la Universidad de Oviedo, 2010, p. 111.

El nuevo gobierno del PP salido de su victoria electoral de finales de 2011 prosiguió las políticas de ajuste y desregulación del mercado de trabajo. La reforma laboral acometida en España en 2012 ha reforzado la descentralización de la negociación e incluso la unilateralidad empresarial en aras de la flexibilidad. En un contexto caracterizado por el minifundismo empresarial y una estructura de representación débil estos cambios favorecen el proceso de "descolectivización" de las relaciones de trabajo. ${ }^{27}$ Además, el estricto cumplimiento de los convenios ha debido resultar más que problemático en un contexto caracterizado en 2013 por altas tasas de desempleo $(26,1 \%)$ y temporalidad $(23,4 \%)$.

\section{CONCLUSIONES}

El trabajo realizado permite concluir que la concertación social competitiva, modelo instaurado en Europa occidental para hacer frente a la crisis de 1992-1996 y acometer las reformas precisas en los países que se insertaron en la Unión Económica y Monetaria de la Unión Europea, resultó adecuado para hacer reformas laborales e impulsar políticas en el ciclo expansivo, pero no durante la actual crisis económica. La ruptura en los países que, en el periodo anterior, habían suscrito acuerdos con asiduidad así lo atestigua.

El caso de España, como se ha expuesto, ha resultado paradigmático. Además, en este caso se evidencian los escasos rendimientos de los acuerdos sociales suscritos (1996-2008) pues no se logró una mejora sustantiva frente a los valores medios de los países de su entorno.

\footnotetext{
${ }^{27}$ BAYLOS GRAU, Antonio P. "La desconstitucionalización del trabajo en la reforma laboral del 2012", Revista de derecho social, $n^{\circ}$ 61, 2013, pp. 19-42. MERINO SEGOVIA, Amparo. "Cambios en la estructura negocial: ¿descentralización o desactivación de la negociación colectiva?”. Lan harremanak: Revista de relaciones laborales, $\mathrm{n}^{\circ} 27,2012$, pp. 37-38.
} 
Pese a que el ciclo expansivo generó empleo, no fue de calidad y continuaron presente una fuerte temporalidad y dualidad en el mercado de trabajo.

Los sindicatos europeos han transitado la etapa de crecimiento económico y acuerdos sociales competitivos sin salir de la misma dinámica regresiva que les ha hecho perder afiliados e influencia económica y social desde la década de 1980. La participación de los sindicatos españoles en la concertación social competitiva no sólo no obtuvo frutos apreciables para sus representados, sino que, en realidad, apenas si logró una mejora muy modesta en términos de penetración social y en las empresas. La mejora de la densidad sindical (pese a destacar en el contexto europeo), la audiencia electoral y la negociación colectiva obtenidas en un ciclo de diez años se paró en seco y retrocedió en apenas dos años, tras el inicio de la actual crisis económica. Toda la labor de responsabilidad y contención realizada durante el periodo de diálogo social, aviniéndose a una desregulación y flexibilidad progresiva del mercado de trabajo no ha sido compensada.

La ruptura del diálogo social, producida con claridad desde mediados de 2010, ha dejado sin apenas capacidad de respuesta a las dos grandes centrales sindicales española. La reforma laboral de 2012, que obviamente no pudieron suscribir y a la que se opusieron, además constriñe más que apreciablemente la intermediación y la contratación colectiva que son una de sus fundamentales razones de ser. La limitación de la negociación colectiva en un país caracterizado por un modelo sindical basado en altas tasas de cobertura en la negociación colectiva y baja densidad sindical, con la limitación de poder celebrar elecciones a representantes unitarios de los trabajadores en empresas de menos de 6 empleados, puede estrangular en buena medida las bases de estas organizaciones. Se generaría así un desequilibrio radical que haría a los sindicatos mayoritarios absolutamente dependientes -además de muy débiles- de la contratación con el gobierno de turno, con independencia de las medidas que realmente se pactaran.

Las reformas laborales suscritas por los sindicatos españoles han sido menos agresivas que las realizadas unilateralmente por el gobierno, a veces con la aquiescencia de la organización de empleadores. Sin embargo, y es lo realmente problemático para los sindicatos, las etapas de consenso apenas si han permitido un fortalecimiento real-desde la base- que les permitiera acumular fuerzas para oponerse con algún viso de éxito a cambios legislativos más agresivos, como los dos últimos realizados en España en 2010 y 2012.

\section{BIBLIOGRAFÍA}

ANTENAS COLLDERREMAN, Josep M. "Los sindicatos ante la globalización. ¿Hacia qué nuevas formas de solidaridad internacional?". Cuadernos de Relaciones Laborales, Vol 26, No 1, 2008, pp. 35-55.

BACCARO, Lucio y SIMONI, Marco. "Policy Concertation in Europe Understanding Government Choice". Comparative Political Studies, vol. 41, no 10, 2008, pp. 1323-1348. 
BAÑOS DÍEZ, Daniel y PÉREZ CUERNO, José Manuel. "Globalización, flexibilidad y neocorporativismo", Revista Universitaria de Ciencias del Trabajo, ํo 6, 2005, pp. 757796.

BAYLOS GRAU, Antonio P. "La desconstitucionalización del trabajo en la reforma laboral del 2012", Revista de derecho social, no 61, 2013, pp. 19-42.

BENEYTO, Pere J. "El sindicalismo español en perspectiva europea: de la anomalía a la convergencia", Cuadernos de Relaciones Laborales. Vol. 26, oㅜ 1, 2008, pp. 57-88.

BENEYTO, Pere J. "Panorama actual de la afiliación sindical", en Observatorio Confederal de Afiliación de CC OO, oํ 1, diciembre, 2009. Disponible en http://www.1mayo.ccoo.es [accedido14/02/2013]

GLASSNER, Vera y POCHET, Philippe. "Why trade unions seek to coordinate wages and collective bargaining in the Eurozone: past developments and future prospects", Working Paper, 03, European Trade Union Institute, 2011. Disponible en: http://www.etui.org/Publications2/Working-Papers/Why-trade-unions-seek-tocoordinate-wages-and-collective-bargaining-in-the-Eurozone [accedido 15/06/2014]

GONZÁLEZ FERNÁNDEZ, Ángeles. "Confrontación y consenso: la concertación social y el juego de intereses en España (1977-2010)", Pasado y Memoria. Revista de Historia Contemporánea, 9, 2010, pp. 101-128.

HYMAN, Richard. "Social dialogue and industrial relations during the economic crisis: Innovative practices or business as usual?", Working Paper No. 11, Industrial and Employment Relations Department, Internacional Labour Organization, 2010. Disponible en: http://www.ilo.org/wcmsp5/groups/public/---ed dialogue/--dialogue/documents/publication/wcms 158355.pdf [accedido 15/05/2014].

JÓDAR, Pere. "Una breve panorámica de las elecciones sindicales de 2011, con apuntes de su evolución desde 2003", Anuario Sociolaboral de 2012, Madrid, Fundación 1ํ de Mayo Comisiones Obreras, 2013. Disponible en: http://www.1mayo.ccoo.es/nova/files/1018/Portada201208.pdf [accedido 15/06/2014].

LÉONARD, Evelyne. "Governance and Concerted Regulation of Employment in Europe", European Journal of Industrial Relations, vol. 11, no 3, 2005, pp. 307-326.

LUQUE BALBONA, David. Las huelgas en España: intensidad, formas y determinantes, Tesis Doctoral, Departamento de Economía Aplicada de la Universidad de Oviedo, 2010. 
Disponible

en:

https://www.educacion.gob.es/teseo/imprimirFicheroTesis.do?fichero=21015 [acceso $15 / 04 / 20141$.

MERINO SEGOVIA, Amparo. "Cambios en la estructura negocial: ¿descentralización o desactivación de la negociación colectiva?". Lan harremanak: Revista de relaciones laborales, no 27, 2012, pp. 35-56.

MIGUÉLEZ, Fausto. “Presentación”. Cuaderno de Relaciones Laborales, Vol. 26 (1), 2008, pp. 9-16.

PÉREZ INFANTE, José I. "La concertación y el diálogo social en España: 1977-2007", Revista del Ministerio de Trabajo e Inmigración, no 81, 2009, pp. 41-70.

REGINI, Marino. "I dilemmi del sindicato del 2000: più rappresentanza per avere influenza o viceversa?", Quaderni di Rassegna Sindícale, nº Speciale Congreso CGIL, 2002.

REGINI, Marino. "Tripartite Concertation and Varieties of Capitalism", European Journal of Industrial Relations, vol. 9, no 3, 2003, pp. 251-263.

RHODES, Martin. "Globalization, Labour Markets and Welfare States: A Future of 'Competitive Corporatism'?". RHODES, M., MÉNY, Y. (Eds.), The Future of European Welfare: A New Social Contract?, London, Macmillan, 1998, pp. 178-203.

RHODES, Martin (2000). "The Polítical Economy of Social Pacts: 'Competitive Corporatism' and European Welfare Reform". PIERSON, P. (Ed.), The new politics of the Welfare State, Oxford, University Press, 2000, pp. 165-196.

ROCHA, Fernando y ARAGÓN, Jorge. Mecanismos de evaluación de los pactos de empleo en las comunidades autónomas: situación y experiencias. Madrid: Fundación 1ํ de Mayo, 2001

SANTOS ORTEGA, Antonio. "La invasión de la ideología empresarial en los márgenes del mercado de trabajo: inseguridad laboral, paro e inserción". Cuaderno de Relaciones Laborales, Vol. 21, № 1, 2003, pp. 107-128.

SCHMITTER, Philippe C. "La concertación social en perspectiva comparada", ESPINA, A. (Comp.), Concertación social, neocorporatismo y democracia, Madrid, Ministerio de Trabajo y Seguridad Social, 1991, pp. 67-80.

SCHMITT, John y MITUKIEWICZ, Alexandra. "Politics matter: changes in unionization rates in rich countries, 1960-2010", Industrial Relations Journal, vol. 43(3), 2012, pp. 260-280. 
Sindicatos, diálogo social y empleo en europa occidental. Una aproximación al caso de españa en perspectiva comparada

SIEGEL, Nico A. "Social Pacts Revisited: 'Competitive Concertation' and Complex Causality in Negotiated Welfare State Reforms". European Journal of Industrial Relations, vol. 11, no 1, 2005, pp. 107-126.

WADDINGTON, Jeremy. "Afiliación sindical en Europa. La magnitud del problema y la variedad de las respuestas sindicales", Documentos de trabajo para la Universidad de verano de la CES/ETUI-REHS de los dirigentes sindicales europeos, 2005. Disponible en http://www.ugt.es/internacional/universidadces/univeranocesafiliacion.pdf consultado $11 / 10 / 2012$ 